\title{
Black esophagus as an autopsy discovery: a challenging interpretation
}

\author{
Anja Kerschen ${ }^{1 *} \mathbb{D}$, Gregory Schmit ${ }^{1,2,3}$, Evy De Boosere ${ }^{4}$, Cristian Palmiere ${ }^{5}$ and Jessica Vanhaebost ${ }^{1,2,3}$
}

\begin{abstract}
Black esophagus is a rare medical condition, characterized by a circumferential blackish discoloration of the distal part of the esophageal mucosa, abruptly ending at the gastroesophageal junction. The etiology is multifactorial since patients suffer from multiple comorbidities. While the mortality rate specifically linked to black esophagus is only around 6\%, the mortality rate linked to the underlying comorbidities amounts to $32 \%$.

A series of five cases is provided in which black esophagus was an unexpected discovery at autopsy. Black esophagus is generally considered being a challenge to the forensic pathologist. There are often no other major gross anomalies found at autopsy and information about the patient's medical history is not always available, which complicates a correct assessment.

We present a review of the literature on black esophagus, limited to reports on deceased patients. The reviewed publications are divided into autopsy and endoscopy series to correctly compare the causes of death.

The aim of this review is to identify a possible divergence in causes of death in autopsy and endoscopy series and additionally to analyze the causes of these differences to enable better assessment and interpretation of black esophagus at forensic autopsies. This paper emphasizes the importance of a minimal knowledge of the victim's comorbidities and medical record and the use of toxicology and postmortem biochemistry analysis as a valuable tool in investigating the cause of death in the setting of black esophagus.
\end{abstract}

Keywords: Black esophagus, Acute esophageal necrosis, Cause of death, Postmortem toxicology, Postmortem biochemistry, Autopsy

\section{Background}

Black esophagus, also known as acute esophageal necrosis (AEN) or acute necrotizing esophagitis, is an uncommon condition characterized by a circumferential blackish discoloration over a various length of the esophageal mucosa ending abruptly at the gastroesophageal junction. Its etiology is considered multifactorial (Gurvits et al. 2007). At present, the "two-hit hypothesis" remains the universally accepted underlying pathophysiological mechanism. The first hit compromises a hypoperfusion state which causes initial damage to the esophageal mucosa and is subsequently followed by a secondary aggression, such as massive acid reflux, resulting in esophageal necrosis (Gurvits et al. 2015; Katsinelos et al. 2003). A recent publication by Jessurun

\footnotetext{
* Correspondence: anja.kerschen@hotmail.com

${ }^{1}$ Department of Pathology, Cliniques Universitaires St Luc, Avenue

Hippocrate, 10, 1200 Brussels, Belgium

Full list of author information is available at the end of the article
}

J. et al. suggests that a microvascular occlusion is a common initial event, which could be a possible explanation for the multitude of comorbidities linked to this pathology (Jessurun et al. 2019).

The incidence of acute esophageal necrosis varies within prior endoscopy and autopsy studies and ranges from 0 to $0.2 \%$ in autopsy series and from less than 0.01 to $0.28 \%$ in endoscopy series (Augusto et al. 2004; Etienne et al. 1969; Lacy et al. 1999; Postlethwait and Musser 1974). Male/female ratio is 4 to 1 , and a peak is noticed around the age of 67. A majority of patients suffers from multiple comorbidities that already result in low vascularization and/or hypotension (Gurvits et al. 2007; Gurvits et al. 2015; Lacy et al. 1999; Ben Soussan et al. 2002). This explains why the overall mortality rate of black esophagus is $5.7 \%$, whereas the mortality rate associated with the underlying comorbidities of black esophagus amounts to $31.8 \%$, based on a literature review from Gurvits et al. (Gurvits et al. 2007). 
The main presentation of black esophagus is upper gastrointestinal bleeding such as hematemesis and/or melena. Esogastroduodenoscopy remains therefore the primary diagnostic tool. A histopathological analysis is considered complementary and therefore not a prerequisite for the diagnosis. Caution is required because of a risk of esophageal perforation when a biopsy is performed during the acute phase. Nevertheless, biopsy could be useful in detecting a possible mycotic superinfection. Treatment is purely supportive (Gurvits et al. 2007; Lacy et al. 1999; Ben Soussan et al. 2002).

Despite the increasing number of published articles in the last decade, black esophagus remains tricky to interpret when encountered during autopsy. After analysis of the recent scientific literature, we noted a substantial difference between autopsy-based and endoscopy-based reports regarding the cause of death. Black esophagus is regularly the only major gross anomaly found during autopsy. Moreover, since forensic pathologists in some countries do not always have access to medical documents, little information is known about patient's medical history, which hampers an accurate evaluation. Similar challenges were also encountered in the series of five cases that we report here. In order to better assess black esophagus discovered during autopsies in the future, we aimed to provide a comprehensive literature review, where the causes of death are compared between autopsy-based and endoscopy-based cases

\section{Case series and literature review}

\section{Series of five cases}

Five cases of black esophagus were discovered during autopsies performed in the period of 2011 to 2016. The mean age in this series amounted 53 with a range from 35 to 87 and a male/female ratio of $4: 1$.

\section{Case 1}

The body of a 37-year-old man was found naked in the shower of his home. The body presented signs of early decomposition. The police had been contacted by worried family members who had been unable to contact their relative for several days. Upon examination of the scene of death, spots of coffee ground vomitus and redbrownish liquid were observed on the kitchen and bathroom floors and on some clothes in a bag close to the body. The same fluid dripped from his mouth onto the thorax. Empty beer cans and bottles were noticed throughout the apartment. Besides alcoholism, there was no known medical history. No traumatic lesions were observed upon examination of the body.

At autopsy, a blackish discoloration of the lower and middle third of the esophagus was discovered (Fig. 1a). The upper digestive tract contained a large volume of a brown-blackish fluid that was comparable to the liquid found at the scene of death. No ulcers or varices were found upon examination of the esophageal, gastric, and duodenal mucosa. Further examination revealed hepatic steatosis, mild atherosclerosis, and cerebral edema.

Toxicology, postmortem biochemistry, and histopathology were not performed. Although acute upper gastrointestinal bleeding was suspected, the precise cause of death was listed as unknown.

\section{Case 2}

A 35-year-old man was found dead in his bathroom by his worried mother. The victim lived isolated from society and showed self-neglect. He suffered from a schizoaffective disorder that was not medically treated, a type 1 diabetes, and overweight (body mass index of $27.3 \mathrm{~kg} /$ $\mathrm{m}^{2}$ ). The patient had been hospitalized 6 months prior to his death for ketoacidosis due to non-compliancy.

The body was altered by decay and situated in fetal position between the door, toilet, and bathtub. Perinasal and peribuccal areas showed black discolorations. Beneath the body, a water bottle of $1.5 \mathrm{~L}$ was found. Marks of blackish fluid were noted on the legs and arms of the body. Similar marks were found on the floor and furniture near the body as well as on toilet paper located in the living room.

At autopsy, black esophagus of the entire surface of the esophageal mucosae was discovered (Fig. 1b). The stomach contained a low quantity $(50 \mathrm{~g})$ of blackish fluid. No ulcers were noted in the esophageal mucosa or the stomach, but discreet atherosclerosis was observed.

Postmortem biochemistry showed high levels of ketone bodies in the blood, urine, and cerebrospinal and pericardial fluids, hyperglycemia in urine and cerebrospinal fluid, and a high blood hemoglobin A1c level. The slightly increased ethanol level in the blood was attributed to decay $(0.39 \mathrm{~g} / \mathrm{kg})$. Traces of bisacodyl (laxative) were also detected.

Histopathological examination was executed on different levels of the esophageal mucosa, which was severely altered by decay in all samples. Epithelium was focally absent. A brown-blackish pigment deposition was observed on the epithelium, if present, or on parts of the submucosa. The rest of the esophageal wall was also severely altered and therefore difficult to assess. No other lesions were found.

Cause of death was assigned to diabetic ketoacidosis secondary to an uncontrolled diabetes. Black esophagus was retained as a rare but known complication to ketoacidosis.

\section{Case 3}

An 87-year-old woman was found death on the floor of her living room. A worried neighbor had peeked through a window and had called for help. Blackish feces 


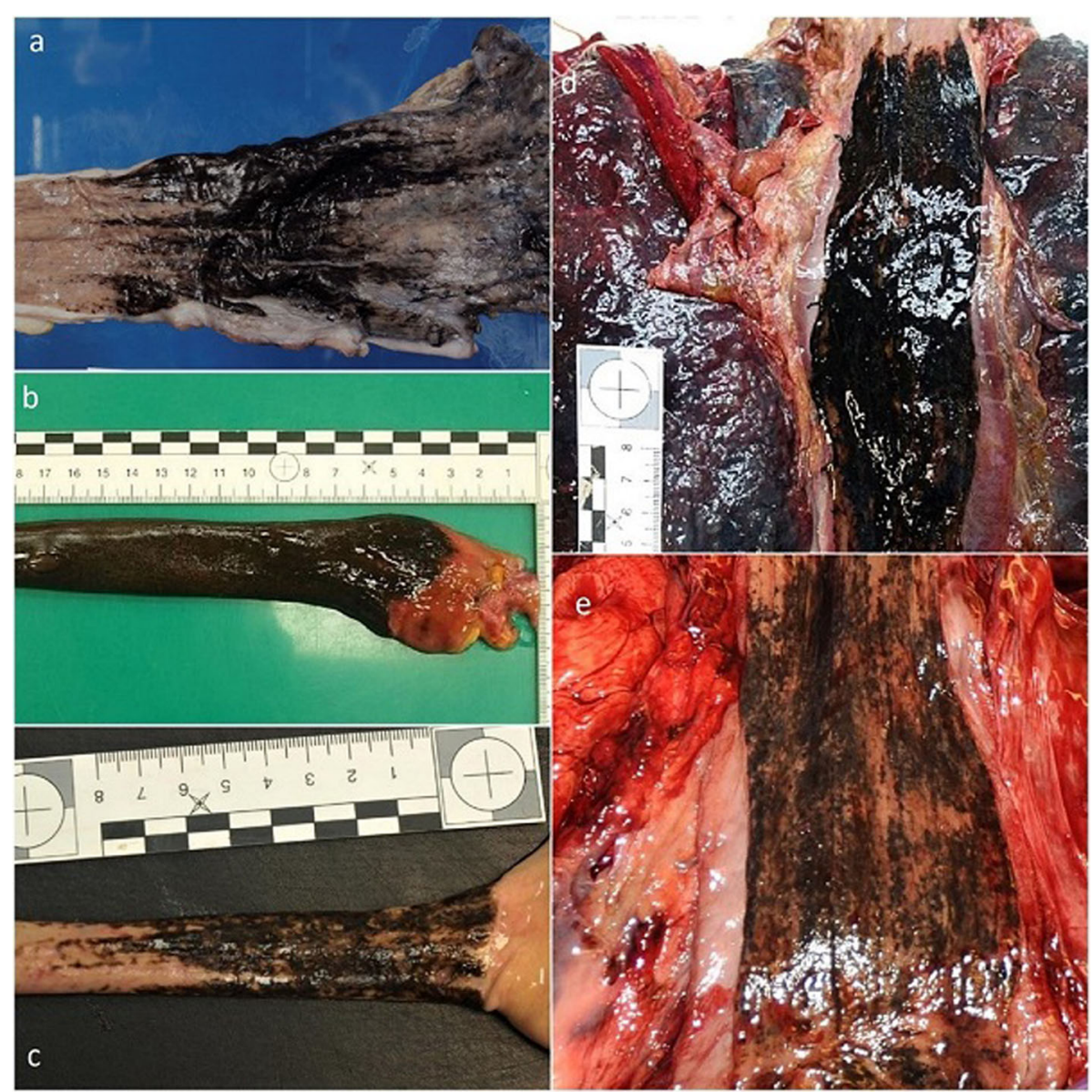

Fig. 1 Gross appearance of black esophagus discovered at autopsy. The pictures of the case series (a-e) illustrate the circumferential blackish discoloration of esophageal mucosa over a various length. $\mathbf{b}$ and $\mathbf{c}$ highlight the sharp ending of black esophagus at gastroesophageal junction (esophagus was turned inside out without opening in $\mathbf{b}$ and $\mathbf{e}$ )

compatible with melena were found in a basin in proximity to the body. The victim was known to have a high blood pressure and cachexia (BMI of $\left.18 \mathrm{~kg} / \mathrm{m}^{2}\right)$. She had suffered a traumatic brain injury with facial fracture 3 months prior to death. An emergency surgery of subdural evacuation was performed 1 month prior to her death. No at-the-scene examination was performed.

On external examination, spots of feces were found on the legs and anal region. The lower limbs showed recent abrasions and ecchymoses. Furthermore, smears of a brownish fluid were spread from the mouth to the left cheek. Lividities were sparse. At autopsy, a massive upper gastrointestinal bleeding with broncho-inhalation of hematinized fluid was discovered. The stomach contained $150 \mathrm{~g}$ of a dark fluid, compatible with digested blood. A similar fluid was found in the esophagus and duodenum. Close to the pylorus, the duodenal mucosa displayed multiple hemorrhagic lesions. The small intestine contained melena. A blackish discoloration of the lower third of the esophageal mucosa was observed (Fig. 1c). Sequela of bilateral trepanation accompanied by residual old subdural hematomas was also noted.

Other findings comprised a generalized, moderate atherosclerosis with renal vascular disease, a left renal cyst, left ventricular hypertrophy and pulmonary edema with discreet pleural effusion ( $20 \mathrm{~mL}$ on both sides), and right sub-pleural petechiae.

A polypoid lesion of the endometrium, measuring $2 \times$ $1 \mathrm{~cm}$, was also found, but a precise diagnostic could not be established, because no sampling for histopathology was performed.

Tissue sampling from the upper, mid, and lower third of the esophagus was performed to allow for histopathological analysis. Examination of the upper third shows thin mucosa with scattered mononuclear cell infiltration. The epithelium and esophageal wall of the mid third did not show any abnormalities. Esophageal mucosa of the lower third shows complete necrosis and was lined by a layer of granulocytes and again brownish pigments. 
Traces of ketone bodies without any glycosuria were detected in urine. High levels of renal function markers, compatible with a metabolic disorder such as feasting, were also measured: creatinine $390 \mu \mathrm{mol} / \mathrm{L}$ (normal values $62-106$ ), urea $27.4 \mathrm{mmol} / \mathrm{L}$ (normal values 2.9 7.7), and urate $790 \mu \mathrm{mol} / \mathrm{L}$ (normal values 202-416).

The forensic pathologist concluded to massive upper gastrointestinal bleeding in the presence of a black esophagus.

\section{Case 4}

The decomposing body of a 69-year-old male was found naked in the bathtub of his apartment. He lived isolated with only few social contacts. His medical history comprised an obstructive sleep apnea syndrome, high blood pressure, moderate hypertensive retinopathy, and hypothyroidism. The patient also suffered from obesity (BMI $33.7 \mathrm{~kg} / \mathrm{m}^{2}$ ).

Red-brownish marks compatible with dried blood were found on the floor throughout the apartment. Bedroom, sheets as well as clothes found in the bathroom and bedroom were stained with the same fluid. Stains with the aspect of liquid stools were discovered in the toilet. The shower curtain lay on the bathroom floor.

On external examination, the red-brownish fluid was found close to the nasal and buccal orifices as well as superficial abrasions of the left knee. The victim had a poor oral hygiene and had only few teeth left.

At autopsy, a black discoloration of the entire esophageal surface was discovered (Fig. 1d). The upper digestive tract, trachea, and larynx contained coffee ground vomitus.

Other findings included severe atherosclerosis of the abdominal aorta and the left carotid bifurcation without stenosis associated with renal vascular disease, cardiomegaly with biventricular hypertrophy, and myocardiosclerosis. Cholelithiasis and few apical pleural adhesions were also found.

Histopathological examination of esophagus was not conclusive due to severe postmortem modifications.

Toxicology and postmortem biochemistry were negative. The slightly increased ethanol level in blood was attributed to decay $(0.33 \mathrm{~g} / \mathrm{kg})$.

Cause of death was related to sudden death in the setting of a black esophagus.

\section{Case 5}

A 38-year-old man was found dead on his knees between the sink and the toilet in his bathroom. The lower part of the body was unclothed. The police had been notified by his work colleagues after a few days of unauthorized absence. Smears of blackish fluid were perceived in proximity to the body. Medical history is unknown, but the victim was likely to be a smoker and consumed alcohol regularly judging by the cigarette packs and empty beer cans spread throughout the apartment.

Red-blackish marks were visible near the mouth and the nose.

At autopsy, the distal third of the esophageal mucosa was discolored black (Fig. 1e). The digestive tract contained a red-blackish fluid. The brain appeared edematous. No other abnormalities were noted.

Postmortem biochemistry showed ketoacidosis related to alcohol abuse.

More specifically, elevated blood ethanol levels were observed in cranial and subdural blood samples $(1.12 \mathrm{~g} / \mathrm{L}$ in cranial blood, $0.86 \mathrm{~g} / \mathrm{L}$ in cardiac blood, $0.2 \mathrm{~g} / \mathrm{L}$ in urine, and $1.07 \mathrm{~g} / \mathrm{L}$ in gastric content) associated with high acetone values $(0.32 \mathrm{~g} / \mathrm{L}$ in subdural blood, $0.28 \mathrm{~g} / \mathrm{L}$ in cardiac blood, $0.99 \mathrm{~g} / \mathrm{L}$ in urine, and $0.04 \mathrm{~g} / \mathrm{L}$ in gastric content) and high isopropanol values $(0.32 \mathrm{~g} / \mathrm{L}$ in subdural blood, $0.26 \mathrm{~g} / \mathrm{L}$ in cardiac blood, $0.10 \mathrm{~g} / \mathrm{L}$ in urine, and $0.18 \mathrm{~g} / \mathrm{L}$ in gastric content). A large toxicology screen for common drugs such as acetaminophen, barbiturates, antidepressants, benzodiazepines and homologous hypnotics, neuroleptics, opioids, cannabinoids, amphetamine derivatives, cocaine and/or metabolites, methadone and/or metabolites, LSD (lysergic acid diethylamide), and GHB (gamma hydroxybutyric acid) was negative when tested in subdural blood, urine, and gastric content.

Black esophagus in a patient under influence of alcohol was retained as the cause of death.

\section{Literature review \\ Method}

PubMed, Scopus Database and GoogleScholar were searched for "Acute esophageal necrosis," "AEN," "esophageal necrosis," "necrotizing esophagitis," "oesophage noir," and "black esophagus." The selection of articles was based on the English and French language, title and abstract. They were subsequently classified into "autopsy" and "endoscopy" series according to whether an esogastroduodenoscopy had been performed prior to death or not.

Only case reports of deceased patients were selected. Case reports published in literature reviews were also included on the condition that patient history was sufficiently detailed. The endoscopy series initially included 88 publications, of which 26 publications on a total of 41 deceased patients were retained (Gurvits et al. 2015; Ben Soussan et al. 2002; Averbukh et al. 2018; Barnes et al. 2014; Day and Sayegh 2010; Del Hierro 2011; Essamri et al. 2001; Grudell et al. 2006; Julian Gomez et al. 2008; Kalva et al. 2016; Katsinelos et al. 2004; Koop et al. 2016; Lahbabi et al. 2013; Maher and Nassar 2008; Odelowo et al. 2002; Ramos et al. 2008; Rodrigues et al. 2016; Roman Fernandez et al. 2014; Salem et al. 2015; 
Shafa et al. 2016; Shah et al. 2017; Sharma et al. 2016; Singh et al. 2011; Wu and $\mathrm{Wu}$ 2014; Monteiro et al. 2019; Khan et al. 2019). The autopsy series initially comprised 13 publications, of which 11 publications on a total of 17 patients were retained in this review. The two excluded autopsy papers included one paper limited to a literature review without any case series and one report focusing on a pathological assessment of black esophagus without any information on patient history (Altenburger et al. 2011; Brennan 1967; Eren et al. 2010; Galtes et al. 2016; Hejna et al. 2013; Keresztesi et al. 2016; Tsao et al. 2014; Tsokos 2011; Tsokos and Herbst 2005; Unuma et al. 2011; Venara et al. 2013). Letters to the editor were not taken into account.

In the endoscopy series, deceased patients who underwent a follow-up esogastroduodenoscopy showing resolution of black esophagus before their death were excluded. One patient had undergone an esophagectomy before death and was therefore excluded too. Case reports addressing black esophagus in the setting of endovascular treatment of aortic aneurysms were excluded. Protheses have been identified as a cause of occlusion of the esophageal vascularization implying that the origin of black esophagus in these cases is purely mechanical, and treatment requires surgery.

Figures were established to compare data from endoscopy and autopsy series.

\section{Results}

In this endoscopy series, male/female ratio is $26: 15$ and mean age is 67.01 years, with a range from 26 to 94 years. The youngest and eldest patients in this series were both female.
Causes of death in the endoscopy series were classified by their frequencies in Fig. 2. The predominant cause of death is multiple organ failure associated with sepsis in approximately half of the cases. The second most frequent cause of death is underlying illness leading to black esophagus. In one of these cases, this was associated with no response to treatment. Only three patients out of 41 succumbed to hemorrhagic shock, comprising two patients who died of upper gastrointestinal bleeding and one patient with a probable thoracic aortic aneurysm rupture.

In eight cases, the cause of death was not revealed in the report, but two out of those eight were likely to have died from hemorrhagic shock. One patient presented rupture of esophageal varices and the other patient died 1 day after esophageal rupture and presented signs of hemorrhagic shock.

In only one case, the cause was attributed to black esophagus in association with persistent sepsis and a deterioration of the patient's condition.

Figure 3 summarizes the medical history and symptoms having led to an upper endoscopy. The main symptom having led to esogastroduodenoscopy is hematemesis followed by hypotension, melena, and coffee ground emesis. Interestingly, 13 of these 41 patients were first hospitalized for treatment of another medical condition such as cancer or bone fractures requiring specialized care. Development of symptoms leading to upper endoscopy and subsequent diagnosis took place either during hospitalization or shortly afterwards. When laboratory test results were investigated, at least 20 of 41 patients had mild to severe anemia.

The medical history of these patients often included hypertension and diabetes. Cardiovascular diseases such

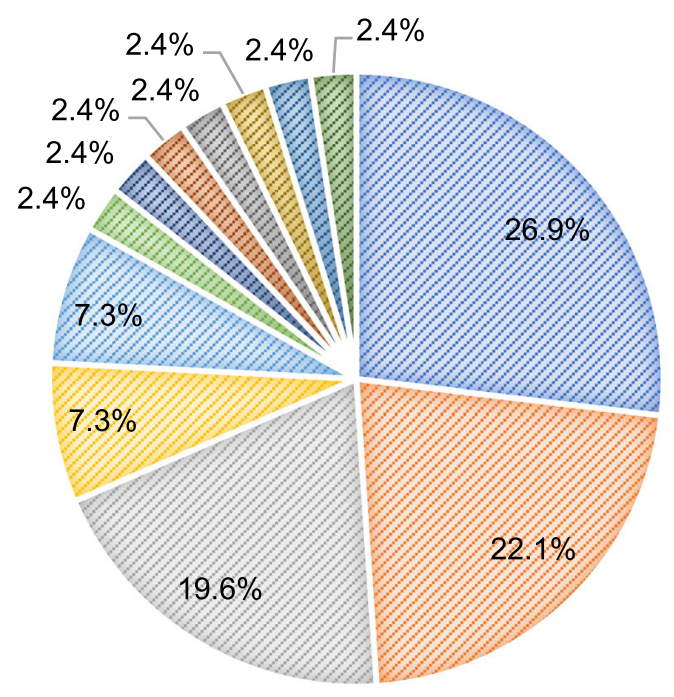

$$
\begin{aligned}
& \text { - MOF +/-sepsis } \\
& \text { " Underlying illness } \\
& \text { " Not specified } \\
& \text { " Neoplasia } \\
& \text { " Hemorrhagic Shock } \\
& \text { " Acute Myocardial Infarction } \\
& \text { - Anoxic encephalopathy } \\
& \text { - Aspiration pneumonia } \\
& \text { - Cardiac arrest (hyperkalemia) } \\
& \text { " Multifactorial } \\
& \text { " Pulmonary embolism } \\
& \text { " BE+sepsis+comorbidities }
\end{aligned}
$$

Fig. 2 Causes of death in the endoscopy series classified by their frequencies. MOF multiple organ failure, BE black esophagus 
Medical History $\quad$ ill Symptoms before EGD

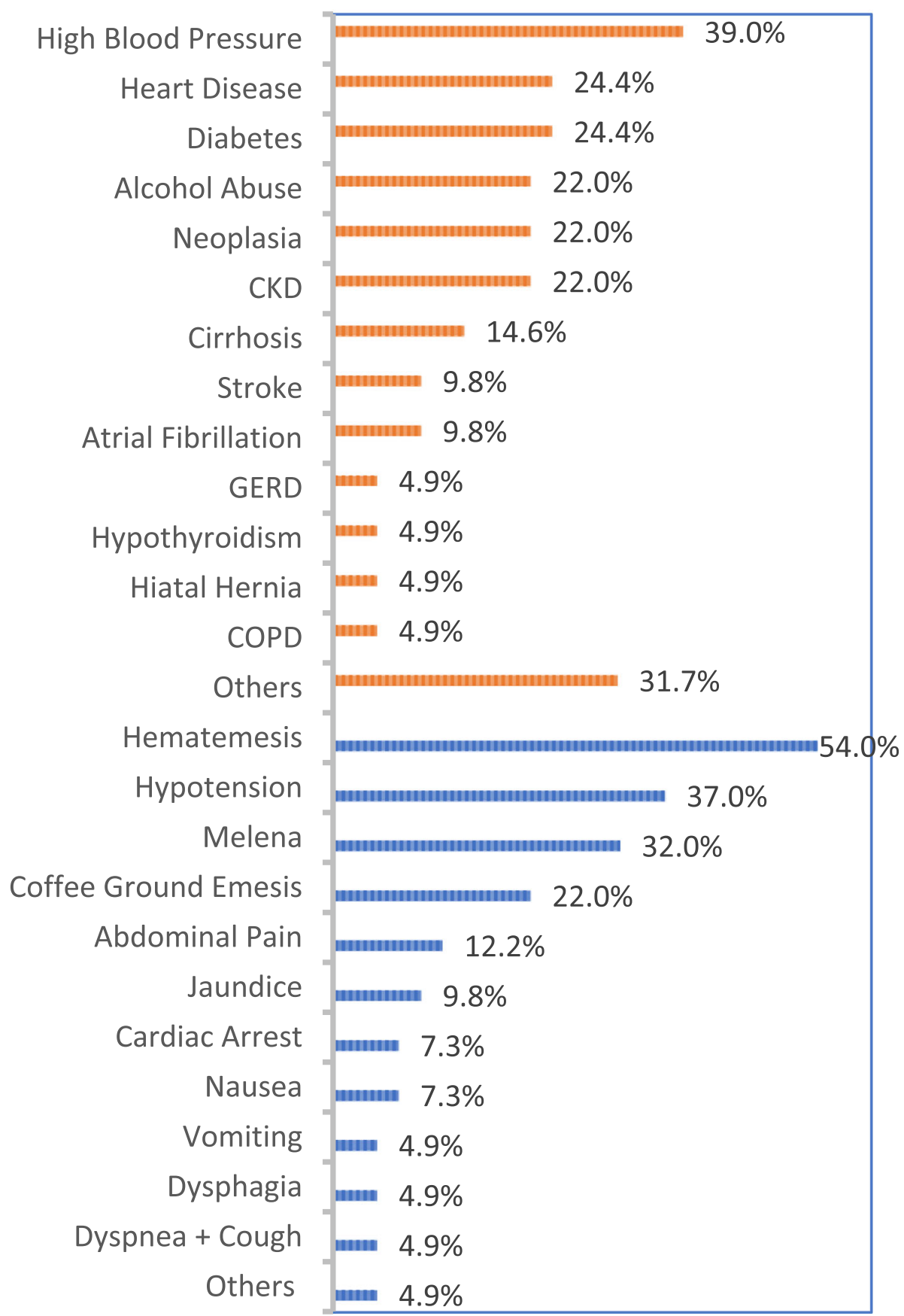

Fig. 3 Figure resuming medical history and symptoms having led to upper endoscopy in the endoscopy series. EGD esogastroduodenoscopy, CKD chronic kidney disease, GERD gastroesophageal reflux disease, COPD chronic obstructive pulmonary disease. Others in symptoms before EGD: acute pancreatitis (1) and hypothermia (1). Others in medical history: abdominal aortic aneurysm (1), thoracic aortic aneurysm (1), asthma (1), diabetic arteriopathy (1), drug abuse (1), diverticulosis (1), lupus erythematosus disseminatus (1), osteoarthritis (1), pancreatitis (recurrent) (1), peripheral vascular disease (1), polyglobulia (1), primary adrenal insufficiency (1), pressure ulcers (1)

as congestive heart failure or acute myocardial infarction were frequently observed as well as alcohol abuse, neoplasia, chronic kidney disease, and liver cirrhosis.
In the autopsy series, the sex ratio is 13 males for 4 females with a mean age of 58 years, ranging from 17 (female) to 83 (male) years. One patient was not taken 
into account in the calculation of the average age, because no precise age was provided in the report ("mid 70ies") (Unuma et al. 2011).

Most patients in the autopsy series were found dead at home, and only three patients died shortly after a hospital admission. These patients had not undergone an upper endoscopy prior to death. One patient died unexpectedly from infected grade 4 decubitus ulcers after being hospitalized for 1 week. One patient had been discovered inanimate outside in a public space, presenting hypothermia. Six patients had a history of coffee ground emesis and/or "malaise" before death.

In Fig. 4, relevant autopsy findings and known medical history were classified by their respective frequencies.

The medical records revealed that more than half of the patients had a history of alcohol abuse and two had a history of drug abuse. Other relevant findings comprised atherosclerosis and diabetes. In three reported cases, the medical history was not mentioned.

At autopsy, liver diseases such as steatosis and cirrhosis were frequently discovered. In four cases, blackish fluid or signs of coffee ground emesis were found.

In four cases, toxicology and/or postmortem biochemistry were not reported. In 11 cases, only alcohol and drug screening (blood and/or urine and/or gastric content) had been performed. Two cases had undergone a more extensive screening, but it is unclear whether any postmortem biochemistry had been performed. In only one case, urine had been screened for ketone bodies and glucosuria.

Causes of death in autopsy series are classified by their frequencies in Fig. 5.

Death was attributed to hemorrhagic shock in the setting of upper gastrointestinal bleeding in three cases. In three cases, cause of death was either not mentioned or unknown. Two patients were supposed to have died of black esophagus. A multifactorial etiology was proposed for two deaths.

\section{Discussion}

Atherosclerosis, alcohol abuse, diabetes, and hypertension are often present in the medical history of the five patients included in our case series. These were also common health issues encountered in the medical history of the patients included in our literature review. After literature review, we did not observe major discrepancies in the medical histories of the patients included in the endoscopy and autopsy series.

Interestingly, there seems to exist two populations of patients, as has been proposed by Gurvits et al. (2015). These comprise a younger population, suffering from alcohol abuse and more likely to present upper gastrointestinal hemorrhage, and a second, older population suffering from multiple comorbidities (Gurvits et al.
2015). This dual presentation is also reflected in our case series of five patients. Cases 1,2 , and 5 were three male patients younger than 40 and two of them abused alcohol. In one case, the cause of death could not be identified, and in the other case, death was assigned to black esophagus in a patient under the influence of alcohol. The third young patient had suffered from mental illness and non-compliant diabetes and subsequently succumbed to diabetic ketoacidosis. The two older patients in our case series suffered from multiple comorbidities which are known risk factors for developing a black esophagus (cases 3 and 4). A similar pattern was noted throughout the autopsy series in our literature review. Younger patients tend to either suffer from alcohol abuse, mental health issues, or both. However, exceptions do exist. Alcohol abuse, combined with other comorbidities, was also noted in patients older than 50, and the youngest patient of the autopsy series (female, 17) died of complications of perforated duodenal ulcers with peritonitis.

The major cause of death in the endoscopy series in our literature review was multiple organ failure, associated with sepsis in approximately half of the cases. In contrast, patients in the autopsy series often succumbed to hemorrhagic shock following upper gastrointestinal bleeding. However, in four cases, cause of death could either not be determined $(2 / 17)$ or was attributed to black esophagus due to lack of other findings $(2 / 17)$. Looking closely at the cases in which cause of death was precise (for example, "respiratory distress in a context of a pulmonary infection"), these autopsies had been performed by pathologists on clinician's request. In these cases, details of the patient's history and background were known, which facilitated the interpretation of the autopsy findings.

As mentioned above, patients in the endoscopy series were frequently hospitalized for another reason and black esophagus was a complication that was usually associated with upper gastrointestinal bleeding. The occurrence of upper gastrointestinal bleeding prompted upper endoscopy and enabled the correct diagnosis and appropriate treatment. The hospital setting clearly differs from patient suddenly presenting with upper gastrointestinal bleeding at home such as case 3 in our case series, who was an 87-year-old woman that died from upper gastrointestinal bleeding at home.

All five cases we reported here died at home, and four out of five were found in their bathroom. Three were partially or completely unclothed. This is also a pattern observed in some patients reported in the autopsy series. Moreover, a red-brownish or blackish fluid was found dripping from nasal and/or oral cavities with stains by a similar liquid elsewhere in the living area and/or close to the body, implying that these stains cannot be solely explained by postmortem regurgitation and sphincter 


\begin{tabular}{|c|c|}
\hline \multicolumn{2}{|r|}{ I Known Medical History } \\
\hline Alcohol abuse & 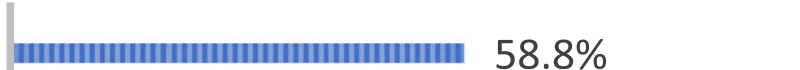 \\
\hline Atherosclerosis & 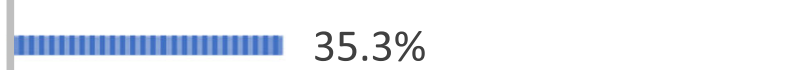 \\
\hline Hematinized fluid in digestive. & 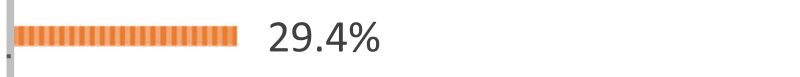 \\
\hline Cirrhosis & 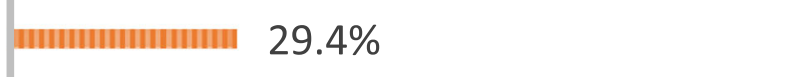 \\
\hline COPD & แกนแกนแนแ $23.5 \%$ \\
\hline Coffee ground fluid in stomach & мининипи $23.5 \%$ \\
\hline Cerebral edema & 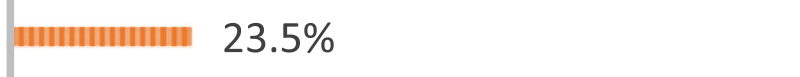 \\
\hline Hepatic steatosis & 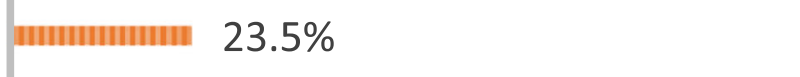 \\
\hline Not mentioned & 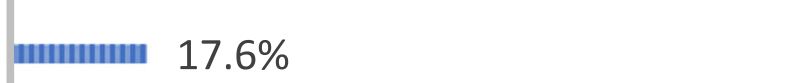 \\
\hline Diabetes & แиนиии $17.6 \%$ \\
\hline Erosive Gastritis & иииนиนиน $17.6 \%$ \\
\hline Pulmonary infection & иинииипи $17.6 \%$ \\
\hline Pulmonary edema & инииниим $17.6 \%$ \\
\hline Drug abuse & แแนแ $11.8 \%$ \\
\hline Sparse lividity and pale organs & $11.8 \%$ \\
\hline Renal carcinoma & пиниш $11.8 \%$ \\
\hline Others & 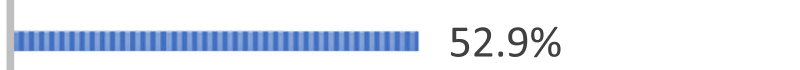 \\
\hline Others & 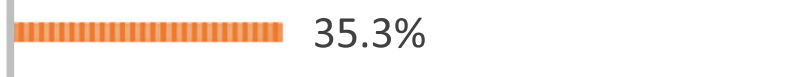 \\
\hline $\begin{array}{l}\text { Fig. } 4 \text { Figure resuming relevant autopsy findings and known medical } \\
\text { pulmonary disease. Others in autopsy findings: myocardial infarct }(1) \text {, } \\
\text { osteomyelitis (1), peritonitis (1), perforated duodenal ulcer (1). Others in } \\
\text { bedridden (1), hemorrhagic stroke (1), alcohol withdrawal for } 6 \text { months }\end{array}$ & $\begin{array}{l}\text { istory by their respective frequencies. COPD chronic obstructive } \\
\text { ronic pancreatitis (1), acute pancreatitis (1), deep decubitus ulcers with } \\
\text { known medical history: intellectual disability (1), psychiatric disorder (1), } \\
\text { (1), seizures (1), high blood pressure (1), smoking (1), none (1) }\end{array}$ \\
\hline
\end{tabular}

releasing. The same fluid was later found in the upper digestive tract of the victims. Two patients presented coffee ground emesis or fluid in their stomach. Furthermore, digested blood combined with gastric acid and digestive juices can cause laxative effects. This assumption is supported by the fact that the patients seemed to feel unwell. They underestimated their condition and thus avoided seeking appropriated medical help.

A case classified in the endoscopy series, reported by Averbukh et al. (Averbukh et al. 2018) illustrates this hypothesis. A 54-year-old man was found unresponsive in a parking lot. He died later in hospital care from persistent hyperkalemia which induced a cardiac arrest. He had a history of repeated hematemesis and was known for alcohol abuse and recurrent pancreatitis. If he had not have been found at the parking lot, he would probably have died there (Averbukh et al. 2018).

Around $23 \%$ of the patients in the endoscopy series of our literature review presented coffee ground emesis. According to Bou-Abdallah et al. 2012, coffee 


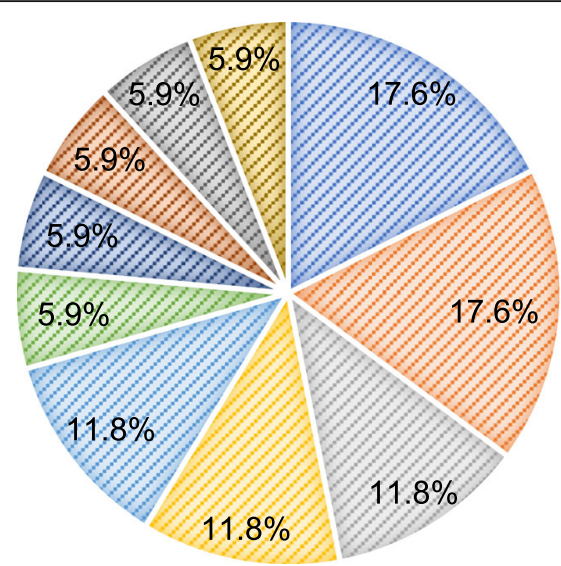

- Hemorrhagic shock

- Unknown / not pointed out

- Multifactorial

- Black Esophagus

- Hepatic failure + Black esophagus

- Cardiac origin

- Respiratory distress

- Hypothermia

- Peritonitis + perforated duodenal ulcer

SSRI + hemorrhage

Fig. 5 Causes of death in autopsy series classified by their frequencies. SSRI selective serotonin receptor inhibitor

ground emesis is a sign of coagulated and digested blood from a subacute, stalled, upper gastrointestinal bleeding. It is frequently related to a mucosal inflammation including esophagitis, gastritis, or duodenitis, and it is often associated with a better prognosis than other causes of upper gastrointestinal bleeding, such as acute bleeding after a rupture of esophageal varices. Coffee ground emesis can also be associated with other origins such as acute myocardial infarction or sepsis, which can both lead to a shock (hypovolemic or cardiogenic) (Bou-Abdallah et al. 2012). According to the large retrospective case series of Augusto et al., in $72.4 \%$ of the cases, no severe hemodynamic repercussions were observed in the upper digestive bleedings in the setting of black esophagus (Augusto et al. 2004).

Overall, there might be a difference between the patients presenting upper digestive hemorrhage causing hemorrhagic shock and those patients presenting coffee ground emesis or regurgitations of a red-brownish fluid (if this is considered as digested blood). Unfortunately, no clear factor has been identified that could enable the identification of those patients who will suffer from massive bleeding or low quantity bleeding.

Nevertheless, a high number of deaths are merely attributed to black esophagus only, whereas none of the deceased patients in the case series reported by Augusto et al. succumbed to acute esophageal necrosis. All patients in that series died because of the underlying health issues (Augusto et al. 2004). As mentioned before, cases from the autopsy series with a precise cause of death originated from autopsies performed by surgical pathologists that were requested by clinicians, whereas the cases without a clear cause of death (undetermined or black esophagus) resulted from autopsies on patients who had been found at home or patients of whom only sparse details about their background were known. The cause of death in three of our five cases is attributed to black esophagus or unknown cause of death. It seems that the macroscopic appearance of black esophagus is so impressive that most pathologists almost desperately want it to be the cause of death, especially if black esophagus is the only major gross finding. However, in endoscopic series, clinicians are aware of the clinical deterioration of their patients, and they can more easily formulate a hypothesis of a possible cause of death. In some countries, forensic pathologists have access to medical records and files, which can enable a detailed assessment. However, this is not possible in every country due to restrictions imposed by the country's judicial system. Unfortunately, those restrictions can affect the access to postmortem biochemistry, toxicology, and histology analysis, and these limitations are often driven by financial reasons. Therefore, conclusions and assumptions are issued from on scene investigations. For instance, if a considerable number of empty beer cans are found in an apartment, the presumption is made that the victim probably abused alcohol. Similar assumptions are made for the presence of cigarettes which is illustrated by our fifth case. Most comorbidities are also discovered by macroscopic changes in organs at autopsy. For example, a fatty liver in an overweighed patient with atherosclerosis can make a forensic pathologist conclude to metabolic syndrome and make him search for complications. But what should be looked for when black esophagus is discovered at autopsy?

Ideally, exhaustive postmortem toxicology and biochemistry should be performed and should not be limited to a mere alcohol and drug screening. This statement is not novel, but given the low numbers of postmortem biochemistry or toxicology analyses performed in the cases presented in this literature review and in our own case series, the need for extensive toxicological and biochemical analyses has to be 
emphasized. A simple urine stick to test for ketone bodies is sometimes sufficient to make the pathologist suspect a diabetic ketoacidosis, which can also be related to black esophagus. The technical procedure is the same as in living patients. The complicated part of postmortem tests is the interpretation of test results. Many factors will alter the values, and in forensic pathology, very little range values exist. This area requires further scientific research, although recent progresses have been made, especially concerning markers for sepsis (Belsey and Flanagan 2016; Maiese et al. 2017). Considering case 5 , the interpretation of postmortem biochemistry was probably not correct. Alcoholic ketoacidosis proven via biochemistry is very likely to be the cause of death, but instead the cause of death was attributed to a black esophagus in a patient under influence of alcohol. In case 1, no toxicology nor biochemistry was performed, and so the precise cause of death remains unknown.

The histopathological examination can provide further details about the victim's health status (hypertension or renal insufficiency for example), but it is not necessarily prerequisite for establishing the diagnosis of black esophagus, which is purely based on the macroscopic aspect (Gurvits et al. 2007). However, because of budget restraints in certain countries, histopathological investigations are not always performed if a third-party involvement (i.e., violent death) is excluded after autopsy. Furthermore, in our five cases, two victims presented signs of putrefaction and therefore histology results could not be correctly interpreted. In the other three cases, no histopathological examination had been performed.

\section{Conclusion}

This case series and the accompanying review of the literature emphasize a clear difference between hospitalized patients who underwent esogastroduodenoscopy and patients passing away at home or shortly after hospital admission without having undergone upper endoscopy. This divergence is also reflected in the causes of death. Black esophagus is often not the reason for hospitalization, and the development of the syndrome is rather a complication occurring during their stay or shortly after it with signs of upper digestive tract hemorrhage such as hematemesis or melena as the main symptom. Help, diagnosis, and treatment are often quickly performed, but patients often succumb due to their multiple underlying comorbidities. Given these circumstances, it is not a surprise that the main cause of death in the endoscopy series is multiple organ failure, which is associated with sepsis in $54.5 \%$ of the cases.

In the autopsy series of our review, however, the main cause of death is hemorrhagic shock following upper gastrointestinal bleeding. This is interesting since hematemesis is one of the main symptoms of black esophagus. It is also remarkable that most of the patients from our own case series were found in the bathroom and partially or completely undressed with signs of regurgitation of a red-brownish fluid compatible with digested blood.

Our case series also confirms the assumptions of Gurvits et al. who reported two different populations suffering from black esophagus: a younger population, abusing alcohol, and a second, older population suffering from multiple comorbidities (Gurvits et al. 2015). In the younger population, mental health issues also seemed to have a high prevalence, which was also observed in the autopsy series upon review of the literature.

Many deaths are either attributed to acute esophageal necrosis due to a lack of information about the patients' medical records or the cause of death remains unknown since black esophagus is often the only major gross finding. However, in the literature review and in our case series, very few postmortem biochemistry or toxicology analyses had been performed. Those analyses could have provided further information about possible medical conditions that do not necessarily cause gross changes, such as diabetic ketoacidosis. It is important to take samples for those analyses, especially when details about the patient's medical history are sparse. This statement is not new. Our work highlights that such sampling is insufficiently performed and analyzed, regardless the underlying (financial or political) reasons.

In conclusion, black esophagus represents a challenging interpretation to the forensic pathologist. However, by searching for further information about the patient's history and comorbidities, interpretation could be made easier, especially when combined with postmortem biochemistry and toxicology analyses.

\section{Abbreviations \\ AEN: Acute esophageal necrosis; BE: Black esophagus; BMI: Body mass index; CKD: Chronic kidney disease; COPD: Chronic obstructive pulmonary disease; EGD: Esogastroduodenoscopy; GERD: Gastroesophageal reflux disease; GHB: Gamma hydroxybutyric acid; LSD: Lysergic acid diethylamide; \\ MOF: Multiple organ failure; SSRI: Selective serotonin receptor inhibitor}

\section{Acknowledgements}

Not applicable.

\section{Authors' contributions}

The five cases of black esophagus originated in autopsies performed by GS, $E d B, C P$, and JV. This rare finding led JV to do some further research about the subject which in turn resulted in the idea of this manuscript. JV and AK collected the data, performed the literature review and data analysis, and cowrote the paper. GS, EdB, and CP contributed to the writing and the page layout. All authors did critical revision of the article and approved the final manuscript.

\section{Funding}

This research did not receive any specific grant from funding agencies in the public, commercial, or not-for-profit sectors. 


\section{Availability of data and materials}

Data sharing is not applicable to this article as no datasets were generated during the current study. The data used to establish the tables and figures are resulting from already published articles which are listed in the references. The method used is explained in the manuscript above.

\section{Ethics approval and consent to participate}

Not applicable.

\section{Consent for publication}

Not applicable.

\section{Competing interests}

The authors declare that they have no competing interests.

\section{Author details}

'Department of Pathology, Cliniques Universitaires St Luc, Avenue Hippocrate, 10, 1200 Brussels, Belgium. ${ }^{2}$ Morphology Reasearch Group, Institute for Experimental and Clinical Reasearch, Université Catholique de Louvain, Brussels, Belgium. ${ }^{3}$ Centre of Forensic Medicine, Cliniques Universitaires St Luc, Avenue Hippocrate, 10, 1200 Brussels, Belgium. ${ }^{4}$ Department of Forensic Medicine, Antwerp University Hospital, Wilrijkstraat, 10, 2650 Edegem, Belgium. ${ }^{5}$ CURML University Center of Legal Medicine, Lausanne University Hospital, Chemin de la Vulliette 4, 1000 Lausanne 25 VD, Switzerland.

\section{Received: 2 August 2019 Accepted: 7 January 2020}

Published online: 07 February 2020

\section{References}

Altenburger DL, Wagner AS, Li S, Garavaglia J (2011) A case of black esophagus with histopathologic description and characterization. Arch Pathol Lab Med 135(6):797-798. https://doi.org/10.1043/2010-0128-C.1

Augusto F, Fernandes V, Cremers MI, Oliveira AP, Lobato C, Alves AL, Pinho C, de Freitas I (2004) Acute necrotizing esophagitis: a large retrospective case series. Endoscopy 36(5):411-415. https://doi.org/10.1055/s-2004-814318

Averbukh LD, Mavilia MG, Gurvits GE (2018) Acute esophageal necrosis: a case series. Cureus 10(3):e2391. https://doi.org/10.7759/cureus.2391

Barnes T, Yan S, Kaakeh Y (2014) Necrotizing esophagitis and bleeding associated with cefazolin. Ann Pharmacother 48(9):1214-1218. https://doi.org/10.1177/ 1060028014537038

Belsey SL, Flanagan RJ (2016) Postmortem biochemistry: current applications. J Forensic Leg Med 41:49-57. https://doi.org/10.1016/j.jflm.2016.04.011

Ben Soussan E, Savoye G, Hochain P, Herve S, Antonietti M, Lemoine F, Ducrotte P (2002) Acute esophageal necrosis: a 1-year prospective study. Gastrointest Endosc 56(2):213-217

Bou-Abdallah JZ, Murthy UK, Mehta N, Prasad HN, Kaul V (2012) Coffee grounds emesis: not just an upper Gl bleed. J Emerg Med 43(1):44-46. https://doi.org/ 10.1016/j.jemermed.2009.05.008

Brennan JL (1967) Case of extensive necrosis of the oesophageal mucosa following hypothermia. J Clin Pathol 20(4):581-584

Day A, Sayegh M (2010) Acute oesophageal necrosis: a case report and review of the literature. Int J Surg 8(1):6-14. https://doi.org/10.1016/j.jjsu.2009.09.014

Del Hierro PM (2011) Acute necrotizing esophagitis followed by duodenal necrosis. Gastroenterology Res 4(6):286-288. https://doi.org/10.4021/gr361w

Eren B, Turkmen N, Fedakar R (2010) Black esophagus: a rare autopsy case. Bratisl Lek Listy 111(7):414-415

Essamri WAFZ, Afifi R, Benazzouz M, Elefeydi Essaid A, Sebti MF (2001) L'oesophage noir - Trois nouvelles observations. Acta Endoscopica 31(5): 709-711

Etienne JP, Roge J, Delavierre P, Veyssier P (1969) Esophageal necrosis of vascular origin. Sem Hop 45(23):1599-1606

Galtes I, Gallego MA, Esgueva R, Martin-Fumado C (2016) Acute oesophageal necrosis (black oesophagus). Rev Esp Enferm Dig 108(3):154-155

Grudell AB, Mueller PS, Viggiano TR (2006) Black esophagus: report of six cases and review of the literature, 1963-2003. Dis Esophagus 19(2):105-110. https:// doi.org/10.1111/j.1442-2050.2006.00549.x

Gurvits GE, Cherian K, Shami MN, Korabathina R, El-Nader EM, Rayapudi K, Gandolfo FJ, Alshumrany M, Patel H, Chowdhury DN, Tsiakos A (2015) Black esophagus: new insights and multicenter international experience in 2014. Dig Dis Sci 60(2):444-453. https://doi.org/10.1007/s10620-014-3382-1
Gurvits GE, Shapsis A, Lau N, Gualtieri N, Robilotti JG (2007) Acute esophageal necrosis: a rare syndrome. J Gastroenterol 42(1):29-38. https://doi.org/10. 1007/s00535-006-1974-z

Hejna P, Ublova M, Vorisek V (2013) Black esophagus: acute esophageal necrosis in fatal haloperidol intoxication. J Forensic Sci 58(5):1367-1369. https://doi. org/10.1111/1556-4029.12151

Jessurun J, Cui I, Aristi-Urista G (2019) Acute (gangrenous) esophageal necrosis (black esophagus). A rare form of injury with specific histologic features and diverse clinical associations with a common pathogenesis. Human Pathol 87: 44-50. https://doi.org/10.1016/j.humpath.2019.02.003

Julian Gomez L, Barrio J, Atienza R, Fernandez-Orcajo P, Mata L, Saracibar E, de la Serna C, Gil-Simon P, Vallecillo MA, Caro Paton A (2008) Acute esophageal necrosis. An underdiagnosed disease. Rev Esp Enferm Dig 100(11):701-705

Kalva NR, Tokala MR, Dhillon S, Pisoh WN, Walayat S, Vanar V, Puli SR (2016) An unusual cause of acute upper gastrointestinal bleeding: acute esophageal necrosis. Case Rep Gastrointest Med 2016:6584363. https://doi.org/10.1155/ 2016/6584363

Katsinelos P, Pilpilidis I, Dimiropoulos S, Paroutoglou G, Kamperis E, Tsolkas P, Kapelidis P, Limenopoulos B, Papagiannis A, Pitarokilis M, Trakateli C (2003) Black esophagus induced by severe vomiting in a healthy young man. Surg Endosc 17(3):521. https://doi.org/10.1007/s00464-002-4248-8

Katsinelos P, Pilpilidis I, Tsolkas P, Galanis I, Papagiannis A, Xiarchos P, Baltagiannis S, Kapelidis P, Vasiliadis I, Kapitsinis IJAoG (2004) Acute esophageal necrosis: is it a so uncommon endoscopic finding? A report of two cases.

Keresztesi AAG, Chinezu L, Jung H (2016) Acute esophageal necrosis ("black esophagus"): case series in forensic autopsies casuistry. Rom J Leg Med 24: 87-91. https://doi.org/10.4323/rilm.2016.87

Khan H, Ahmed M, Daoud M, Philipose J, Ahmed S, Deeb L (2019) Acute esophageal necrosis: a view in the dark. 13. https://doi.org/10.1159/ 000496385

Koop A, Bartel MJ, Francis D (2016) A case of acute esophageal necrosis and duodenal disease in a patient with adrenal insufficiency. Clin Gastroenterol Hepatol 14(10):A17-A18. https://doi.org/10.1016/j.cgh.2016.06.026

Lacy BE, Toor A, Bensen SP, Rothstein Rl, Maheshwari Y (1999) Acute esophageal necrosis: report of two cases and a review of the literature. Gastrointest Endosc 49(4 Pt 1):527-532

Lahbabi M, Ibrahimi A, Aqodad N (2013) Acute esophageal necrosis: a case report and review. Pan Afr Med J 14:109. https://doi.org/10.11604/pamj.2013. 14.109.2000

Maher MM, Nassar MI (2008) Black esophagus: a case report. Cases J 1(1):367. https://doi.org/10.1186/1757-1626-1-367

Maiese A, Del Nonno F, Dell'Aquila M, Moauro M, Baiocchini A, Mastracchio A, Bolino G (2017) Postmortem diagnosis of sepsis: a preliminary immunohistochemical study with an anti-procalcitonin antibody. Leg Med (Tokyo) 28:1-5. https://doi.org/10.1016/j.legalmed.2017.07.002

Monteiro JMC, Castelo LF, Fischer WGG, Felipe-Silva A (2019) Black esophagus. Autops Case Rep 9(1):e2018077. https://doi.org/10.4322/acr.2018.077

Odelowo OO, Hassan M, Nidiry JJ, Marshalleck JJ (2002) Acute necrotizing esophagitis: a case report. J Natl Med Assoc 94(8):735-737

Postlethwait RW, Musser AW (1974) Changes in the esophagus in 1,000 autopsy specimens. J Thorac Cardiovasc Surg 68(6):953-956

Ramos R, Mascarenhas J, Duarte P, Vicente C, Casteleiro C (2008) Acute esophageal necrosis: a retrospective case series. Rev Esp Enferm Dig 100(9):583-585

Rodrigues BD, Dos Santos R, da Luz MM, Chaves ESF, Reis IG (2016) Acute esophageal necrosis. Clin J Gastroenterol 9(6):341-344. https://doi.org/10. 1007/s12328-016-0692-1

Roman Fernandez A, Lopez Alvarez A, Fossati Puertas S, Arean Gonzalez I, Varela Garcia O, Viano Lopez PM (2014) Black esophagus (acute esophageal necrosis) after spinal anesthesia. Rev Esp Anestesiol Reanim 61(7):401-403. https://doi.org/10.1016/.redar.2013.06.001

Salem GA, Ahluwalia S, Guild RT (2015) A case of acute oesophageal necrosis (AEN) in a hypothermic patient. The grave prognosis of the black oesophagus. Arab J Gastroenterol 16(3-4):136-138. https://doi.org/10.1016/j. ajg.2015.05.002

Shafa S, Sharma N, Keshishian J, Dellon ES (2016) The black esophagus: a rare but deadly disease. ACG Case Rep J 3(2):88-91. https://doi.org/10.14309/cri.2016.9

Shah A, Thoguluva Chandreskar V, Doobay R, Kahlon A, Amzuta I (2017) Acute esophageal necrosis in an alcoholic after successful resuscitation from cardiac arrest. Case Rep Gastrointest Med 2017:5092906. https://doi.org/10. 1155/2017/5092906 
Sharma V, De A, Ahuja A, Lamoria S, Lamba BM (2016) Acute esophageal necrosis caused by candidiasis in a patient with systemic lupus erythematosus. J Emerg Med 51(1):77-79. https://doi.org/10.1016/j.jemermed.2016.04.005 Singh D, Singh R, Laya AS (2011) Acute esophageal necrosis: a case series of five patients presenting with "Black esophagus". Indian J Gastroenterol 30(1):41-45. https://doi.org/10.1007/s12664-011-0082-z

Tsao C, Thomas L, McGoey RR (2014) Pathology image of the month. Black esophagus detected at autopsy in a patient with abdominal pain and bloody diarrhea. DIAGNOSIS: acute esophageal necrosis, ischemic and pseudomembranous colitis. J La State Med Soc 166(4):188-190

Tsokos M (2011) Black esophagus. Forensic Sci Med Pathol 7(4):374-376. https:/ doi.org/10.1007/s12024-011-9222-0

Tsokos M, Herbst H (2005) Black oesophagus: a rare disorder with potentially fatal outcome. A forensic pathological approach based on five autopsy cases. Int $J$ Legal Med 119(3):146-152. https://doi.org/10.1007/s00414-004-0509-5

Unuma K, Harada K, Funakoshi T, Uemura K (2011) Sudden death of an alcoholic elderly man with acute esophageal necrosis (black esophagus). Forensic Sci Int 212(1-3):e15-e17. https://doi.org/10.1016/j.forsciint.2011.05.024

Venara A, Pavageau AH, Maillart CR, Jousset N (2013) Sudden death due to black esophagus: a case report. Am J Forensic Med Pathol 34(1):16-17. https://doi. org/10.1097/PAF.0b013e3182717b98

Wu MH, Wu HY (2014) Incremental change in acute esophageal necrosis: report of two cases. Surg Today 44(2):363-365. https://doi.org/10.1007/ s00595-013-0526-4

\section{Publisher's Note}

Springer Nature remains neutral with regard to jurisdictional claims in published maps and institutional affiliations.

\section{Submit your manuscript to a SpringerOpen ${ }^{\circ}$ journal and benefit from:}

- Convenient online submission

- Rigorous peer review

- Open access: articles freely available online

- High visibility within the field

- Retaining the copyright to your article

Submit your next manuscript at $\boldsymbol{\nabla}$ springeropen.com 